\title{
Optimal Magnitude and Probability of Fines *
}

\author{
Nuno Garoupa ${ }^{\dagger}$ \\ Universitat Pompeu Fabra
}

April 2, 2000

\begin{abstract}
The economic literature on crime and punishment focuses on the trade-off between probability and severity of punishment, and suggests that detection probability and fines are substitutes. In this paper it is shown that, in presence of substantial underdeterrence caused by costly detection and punishment, these instruments may become complements. When offenders are poor, the deterrent value of monetary sanctions is low. Thus, the government does not invest a lot in detection. If offenders are rich, however, the deterrent value of monetary sanctions is high, so it is more profitable to prosecute them.
\end{abstract}

\section{JEL: K4}

Keywords: crime, probability and severity of sanctions, law enforcement

*This paper has benefited from suggestions and comments by Hugh Gravelle, Mitch Polinsky, Steven Shavell, two anonymous referees and the Editor, Klaus Schmidt. I am grateful to Kelly Markva for research assistantship. Financial support from FLAD, Lisbon, Portugal is gratefully acknowledged. The usual disclaimer applies.

†Department d'Economia i Empresa, Universitat Pompeu Fabra, Ramon Trias Fargas 25-27, 08005 Barcelona, Spain. Phone: 34-93-542 2639. Fax: 34-93-542 1746. Email: nuno.garoupa@econ.upf.es 


\section{Introduction}

The proposition that crime rates respond to risks and benefits is called the deterrence hypothesis. It is an application of the theory of demand to one of the most important issues in criminal justice. The hypothesis asserts that people respond significantly to the incentives created by the criminal justice system. If so, increasing the resources that society devotes to the arrest, conviction, and punishment of criminals will reduce the amount and social cost of crime.

Suppose that there is a particular offense that we wish to deter, say, illegal parking. It might be possible to eliminate illegal parking, or very nearly eliminate it, by imposing a severe punishment with high probability. However, deterring illegal parking in this way may run into a cost problem. Apprehending, prosecuting, and punishing offenders can be expensive. Policy-makers should balance these costs against the advantages of reducing illegal parking. ${ }^{1}$

In this paper, we reconsider the high fine-low probability result by Becker (1968): When deciding whether or not to commit an act, an individual compares the benefit from the act with the expected punishment. The expected punishment is given by the probability of detection and punishment times a monetary sanction. A fine is a costless transfer from the convicted offender to the government. In contrast, detection is expensive. Consequently, the government should set the fine equal to an offender's entire wealth and complement it with the appropriate probability in order to achieve optimal deterrence. This high fine-low probability result suggests the following corollary: If the agents' wealth goes up, the government should increase the sanction and, at the same time, reduce the probability of detection. That way the government still provides for optimal deterrence, but saves resources on law enforcement.

\footnotetext{
${ }^{1}$ See Garoupa (1997), and Polinsky and Shavell (2000).
} 
We show that this corollary (the substitutability between fine and probability) only holds if the social optimum involves nearly full deterrence. If there is substantial underdeterrence (the expected fine is significantly less than the social damage caused by the offense), then there is a complementary relationship between the two variables. When the fine goes up, so should the probability of detection.

In order to understand this result, consider a rather extreme case where the agent's wealth is zero. In this case, fines are zero and the deterrent value is zero. Thus, it makes absolutely no sense to spend money on enforcement. When wealth goes up, so do fines. Now it becomes worthwhile for the government to engage in detection and punishment. As a consequence, we have a complementary relationship between fine and probability when there is substantial underdeterrence (alternatively, when offenders are poor). This contrasts with the conventional substitutability which holds if the expected sanction is close to the social damage caused by the offense.

The paper is organized as follows: the result is formally derived in section two; final remarks are addressed in section three. All proofs are relegated to the appendix.

\section{The model}

Risk-neutral individuals choose whether or not to commit an act that benefits the actor by $b$ and harms the rest of society by $h$. The policy-maker does not know any individual's $b$ but knows the distribution of parties by type described by a general density function $g(b)$ with support $[0, \infty)$, a cumulative distribution $G(b)$, and a distribution elasticity $\epsilon(b)=-g^{\prime}(b) b / g(b)$. Some acts are socially beneficial: $h<\infty$.

The government chooses a sanction, $f$, and a probability of detection and conviction, $p$. The expenditure on detection and conviction to achieve a probability $p$ is given by $x(p)$, where $x_{p}>0$ and $x_{p p} \geq 0$. The maximum 
feasible sanction is $F$, which can be interpreted as the maximum wealth of individuals. We further assume that the sanction is costless to impose and collect. The objective function to be maximized is the sum of individuals' benefits minus the harm caused by their acts and enforcement costs. ${ }^{2}$

Risk-neutral individuals commit an offense if and only if $b \geq p f$. Given each individual's decision to be honest or dishonest, social utility is:

$$
W=\int_{p f}^{\infty}(b-h) d G(b)-x(p)
$$

The government maximizes the welfare function with respect to $f$ (severity of punishment) and $p$ (probability of punishment) subject to $f \leq F .^{3}$ The public sector budget is financed by lump-sum taxation.

Proposition 1 (1) The optimal fine is the maximal fine. (2) The optimal probability of detection and conviction satisfies $F\left(h-p^{*} F\right) g\left(p^{*} F\right)=x_{p}\left(p^{*}\right)$.

(3) Some underdeterrence is optimal.

We have formally derived Becker's argument. We can now establish that the optimal probability is not necessarily monotonically decreasing in the maximal fine.

Proposition 2 (1) If $\epsilon\left(p^{*} F\right)<1$, the optimal probability increases with the maximal fine if the expected sanction is less than $h(1-\epsilon) /(2-\epsilon)$. (2) If $\epsilon\left(p^{*} F\right) \geq 1$, the optimal probability is monotonically decreasing in the maximal fine.

\footnotetext{
${ }^{2}$ We use the conventional social welfare functional. The inclusion of illegal gains is controversial and has been questioned by several scholars. See Lewin and Trembull (1990) and Polinsky and Shavell (2000). Shavell (1985) acknowledges that there may be a divergence between social value and private gain. The divergence could be expressed by inserting a coefficient of social value in this model.

${ }^{3}$ We study non-trivial solutions. Therefore, we ignore the following constraints: $f \geq 0$ and $0 \leq p \leq 1$. We assume that these constraints are not binding.
} 
Comparative statics show that the optimal probability of detection is not monotonically decreasing in the maximal fine as implicitly assumed in the literature.

If the maximal fine is high, the level of deterrence is also high and the difference between full internalization and optimal deterrence is small. If $F$ increases, the probability $p$ can be reduced, achieving the same deterrence level at lower enforcement costs. This is Becker's trade-off.

However, if the maximum fine is very small, the level of deterrence is very low. In this case, an increase in $\mathrm{F}$ increases the deterrence value of any given $p$ substantially and thus makes it more profitable to increase $p$. Thus, in this range the probability and magnitude of fines are complements rather than substitutes.

At lower levels of deterrence the gain in deterrence dominates enforcement costs. At higher levels of deterrence the increase in costs dominates the gain in deterrence. Continuity suggests that there is a turning-point in between, which is confirmed by Proposition 2.

A simple example helps to understand the result: When people are poor, the deterrent value of monetary sanctions is low. Given this observation, we do not want to invest a lot in catching people (if sanctions were limited to one penny, the deterrent value of sanctions would be essentially zero, so we would hardly spend anything on catching people). If people are rich, however, then the deterrent value of monetary sanctions is high, so it is worth investing in catching them. Hence, the wealthier, but not the wealthiest, should face a higher probability of detection for the same offense, since the wealthiest individuals will face a sufficiently high sanction.

This result prevails as long as the elasticity of deterrence with respect to the expected fines is relatively low. Otherwise, the increase in deterrence from increasing the expected sanction is large enough to make sure that Becker's trade-off holds. 
Proposition 3 When the maximal fine $F$ increases, the expected sanction also increases.

When probability and severity of punishment are substitutes, an increase of the maximal fine always dominates the consequent reduction of the probability of punishment in such a way that the expected sanction increases. Take the limit case where the expected sanction equals the harm $h$. Then an increase of the maximal fine is exactly offset by the reduction of the probability of punishment. However, we know that the expected fine is less than $h$ because enforcement is costly. Therefore, when the maximal fine increases, we can reduce the probability (saving on enforcement costs), but not to the point of exactly offsetting the increase of the maximal fine (making further gains in deterrence). From Proposition 1, we know that the level of underdeterrence is decreasing in the maximal fine. To see this, we can write $\left(h-p^{*} F\right) g\left(p^{*} F\right)=x_{p}\left(p^{*}\right) / F$. The level of underdeterrence increases when the marginal cost of enforcement relative to the value of the assets forfeited increases. An increase of the maximal fine implies that this relative value decreases, so the level of underdeterrence also decreases.

\section{Final Remarks}

In this paper, we have argued that the trade-off between probability and severity of punishment may not be consistent with optimal law enforcement when there is substantial underdeterrence. When the optimal expected sanction is sufficiently large, we approach complete deterrence (the negative externality is fully internalized). By increasing the maximal fine, we can relax the probability achieving the same deterrence level and saving on enforcement costs. However, when the optimal expected sanction is low, we have substantial underdeterrence. By increasing the maximal fine, we should also increase the probability making further gains in deterrence. 
The maximal fine has been interpreted as the entire wealth of an individual throughout this paper; all individuals having the same wealth. Polinsky and Shavell (1991) have considered the case where wealth varies among individuals. An individual's wealth is observed once detected and convicted but not beforehand. Therefore, the severity of punishment is conditional on wealth but not the probability of punishment. In our model, both the severity and probability of punishment have been conditional on wealth. In other words, in our model, a potential offender's wealth is observable before detection and conviction.

Polinsky and Shavell essentially say that any individual, when detected, should pay a monetary sanction given by the harm divided by the probability. ${ }^{4}$ However, if the offender cannot afford it, he pays his entire wealth (the maximal fine in Becker's sense). Those that are able to pay the fine are completely deterred since their expected sanction equals the social damage they cause. Those that are not able to pay the fine, and lose their entire wealth, are underdeterred since their expected sanction is less than the harm they cause. We have shown in our model that such policy is not optimal when wealth is observable before detection. Within our model both groups are underdeterred because every potential offender faces an expected sanction less than the harm they cause.

When wealth is not observable before detection, the probability is the same for all offenders. When wealth is observable before detection, our result shows that the probability of detection and conviction is concave in wealth: The optimal probability is low when the sanction is too low (because it is not profitable to prosecute these individuals) and when the sanction is sufficiently large (the usual Becker's trade-off). In the formulation given by Polinsky and Shavell, very poor individuals and very wealthy individuals face a probability which is too high. For wealthy individuals, the fact that the

\footnotetext{
${ }^{4} \mathrm{~A}$ result known in the literature as the 'multiplier principle'.
} 
government cannot observe wealth beforehand means that they bear a lower sanction and a higher probability than when wealth is observable beforehand (Becker's usual argument). As for very poor individuals, they also face a higher probability because it is not worthwhile for the government to invest in catching these offenders (the sanction is already at its highest feasible value).

\section{References}

1. Becker, G. S., 1968. Crime and punishment: an economic approach, Journal of Political Economy 76, 169-217.

2. Garoupa, N., 1997. The theory of optimal law enforcement, Journal of Economic Surveys 11, 267-295.

3. Kaplow, L., 1992. The optimal probability and magnitude of fines for acts that definitely are undesirable, International Review of Law and Economics 12, 3-11.

4. Lewin, J. F. and Trumbull, W. N., 1990. The social value of crime?, International Review of Law and Economics 10, 271-284.

5. Polinsky, A. M., and Shavell, S., 1984. The optimal use of fines and imprisonment, Journal of Public Economics 24, 89-99.

6. Polinsky, A. M., and Shavell, S., 1991. A note on optimal fines when wealth varies among individuals, American Economic Review 81, 618621.

7. Polinsky, A. M., and Shavell, S., 1992. Enforcement costs and the optimal magnitude and probability of fines, Journal of Law and Economics 35, 133-148. 
8. Polinsky, A. M., and Shavell, S., 2000. The economic theory of public enforcement of law, Journal of Economic Literature, forthcoming.

9. Shavell, S., 1985. Criminal law and the optimal use of nonmonetary sanctions as a deterrent, Columbia Law Review 85, 1232-1262.

10. Shavell, S., 1993. The optimal structure of law enforcement, Journal of Law and Economics 36, 255-287.

\section{Appendix: Proof of Propositions}

\section{Proof of Proposition 1}

Define the Lagrangean function as $L=W+\lambda(F-f)$. The optimal $f^{*}$ and $p^{*}$ must satisfy :

$$
\begin{gathered}
L_{f}=p(h-p f) g(p f)-\lambda=0 \\
L_{p}=f(h-p f) g(p f)-x_{p}=0
\end{gathered}
$$

where $L$ is the Lagrangean, and $\lambda$ is the Lagrangean multiplier. Suppose the optimal fine is not maximal. From $(2)$, we have $p^{*} f^{*}=h$. However, from (3), we know that this is impossible because $L_{p}<0$. Hence, the optimal solution must be $f^{*}=F$ and $\lambda^{*}>0$.

From (3), one may find an interior solution for the probability such that:

$$
F\left(h-p^{*} F\right) g\left(p^{*} F\right)=x_{p}\left(p^{*}\right) \Rightarrow p^{*} F<h
$$

Checking the second-order condition

$$
W_{p p}=-F^{2} g\left(p^{*} F\right)-x_{p p}\left(p^{*}\right)+F^{2}\left(h-p^{*} F\right) g^{\prime}\left(p^{*} F\right)
$$

The second-order condition is satisfied as long as $x($.$) exhibits sufficiently$ decreasing returns to scale. 


\section{Proof of Proposition 2}

By the implicit function theorem, we have that the sign of $\partial p^{*} / \partial F$ is given by the sign of $W_{p F}$ :

$$
\begin{aligned}
W_{p F} & =\left(h-2 p^{*} F\right) g\left(p^{*} F\right)+\left(h-p^{*} F\right) p^{*} F g^{\prime}\left(p^{*} F\right) \\
& =g\left(p^{*} F\right)\left[\left(h-2 p^{*} F\right)-\left(h-p^{*} F\right) \epsilon\left(p^{*} F\right)\right]
\end{aligned}
$$

The result is clear.

\section{Proof of Proposition 3}

Define $z=p^{*} F$. We must show that $z_{F}=p^{*}-F W_{p F} / W_{p p}>0$, or equivalently, $F W_{p F}>p^{*} W_{p p}$ :

$$
\begin{gathered}
F W_{p F}=g\left(p^{*} F\right)\left[\left(h-2 p^{*} F\right) F-\left(h-p^{*} F\right) F \epsilon\left(p^{*} F\right)\right] \\
p^{*} W_{p p}=-g\left(p^{*} F\right)\left[p^{*} F^{2}+\left(h-p^{*} F\right) F \epsilon\left(p^{*} F\right)\right]-p^{*} x_{p p}
\end{gathered}
$$

We can also observe that:

$$
F W_{p F}-p^{*} W_{p p}=\left(h-p^{*} F\right) F g\left(p^{*} F\right)+p^{*} x_{p p}>0
$$

The result follows. $\square$ 